\title{
Does Liquidity Risk Explain the Time-Variation in Asset Correlations? Evidence from Stocks, Bonds and Commodities
}

\author{
Zintle Twala ${ }^{1}$, Riza Demirer², Rangan Gupta ${ }^{1 *}$ \\ ${ }_{1}^{1}$ Department of Economics, University of Pretoria, Pretoria, South Africa \\ ${ }^{2}$ Department of Economics \& Finance, Southern Illinois University Edwardsville, Edwardsville, USA \\ u11084482@tuks.co.za, rdemire@siue.edu, rangan.gupta@up.ac.za*
}

\begin{abstract}
The time-variation in asset correlations have broad implications in asset pricing, portfolio management and hedging. Numerous studies in the literature have found that the change in correlations is mainly related to the magnitude of market movements, hence volatility. However, recent research finds that the size of markets fluctuations is not necessarily the primary driver for the time-variation in correlations, but that the effect of market movements is amplified in times of high financial distress, characterised by low liquidity. This paper seeks to investigate the effect of liquidity on time-varying correlations among different asset classes, namely stocks, corporate bonds and commodities. Our findings show that liquidity indeed has a significant effect on the time-variation in asset correlations, particularly in the case of how bond returns comove with other asset classes. We observe that higher liquidity risk is associated with lower correlation of bond returns with stocks as well as commodities. Our findings suggest that measures of liquidity risk can improve models of correlations; and potentially help improve the effectiveness of risk management strategies during periods of financial distress.

JEL Codes: C22, G10.
\end{abstract}

Keywords: Conditional correlation, Asset Classes, Liquidity and Volatility

\section{Introduction}

Correlations are critical in portfolio allocation decisions and assessing risks associated with investment positions. The modern portfolio theory (Markowitz, 1952) is built upon the notion that investors can diversify away asset specific risks by allocating investment positions to assets with low correlations in order to eliminate as much diversifiable risk as possible in the portfolio. As such, investors measure the correlation coefficients between the returns of different assets and strategically identify asset combinations that will result in a balanced portfolio composition. However, the empirical evidence from the finance literature suggests that correlations are not stable and are in fact highly variable, depending on the state of the market. As Engle (2002) notes, return correlation and volatilities follow a dynamic pattern as asset co-movements adjust to the most recent information. Hence, in order to maintain an optimally diversified portfolio, it is of critical importance to identify the drivers of correlations in order to accurately forecast correlations of returns (Engle, 2002).

There has been extensive work in measuring and understanding the basis for the time-variation in correlations, specifically when it comes to their relation to market movements. Clearly, from a risk averse investor's perspective, diversification is needed the most during periods of market turbulence. Campbell, Koedijk, and Koftnan (2002) state that thecorrelation estimates that are conditional on the size of market movements are mostly relevant to investment analysts in times of extreme market conditions characterized by large price movements. During bearish market periods, investors can benefit from diversification as a decline in the value of some assets can be offset by a rise in the value of the others. Consequently, a number of studies including Ramchand and Susmel (1998), Longin and Solnik (1995), Boyer, Gibson and Loretan, (1999), and Loretan and English (2000) have proposed correlation estimates conditional on market returns below or above a specific threshold. However, Campbell, Koedijk, and Koftnan (2002) suggest that these studies suffer from a theoretical estimation bias, as correlation is not only dependent on the size of market movements, but is affected by the market state asymmetrically in that it increases specifically in bearish market states. This observation suggests that the state of the market serves as an indirect driver of correlation and instead, there is an underlying market factor that brings about the market state effect on correlations. Our goal in this study is to examine whether market liquidity plays a role as the underlying market factor. 
The motivation of our study stems primarily from Moro and Beker(2016) who characterise financial crises as the combination of asymmetric information and illiquidity that gives rise to the possibility of a funding crisis, a situation whereby all depositors want their cash back. In line with an earlier study by Amihud, Mendelson and Wood (1990) which found that the crash of 1987 occurred particularly due to the rise in market illiquidity, Moro and Beker (2016) further state that a security crisis is associated with an increase in demand for more liquid securities. In another related work, Pástor and Stambaugh (2003) also found that their liquidity measure sharply dropped in times of severe financial distress. In fact, in a recent study, examining the time-varying correlations between equity and currency returns, Jung (2017) argue that idiosyncratic volatility driven by the volatility in market liquidity acts as a channel that drives the time-variation in currency-equity correlations.All this evidence raises a question as to whether liquidity could possibly serve as the underlying factor, drivingthe time-variation incorrelations and/or amplifying the effect of volatility on correlations among asset classses, particularly in times of financial distress.

This paper examines the effect of liquidity on the time-variation in the correlations among three major asset classes, particularly stocks, corporate bonds and commodities. Given the evidence in the literature, it seems reasonable to expect investors to require higher returns for illiquid assets (Pastor \& Stambaugh, 2003). Hence, it is hypothesized that asset correlations will partially be driven by their exposure to market liquidity shocks, leading to a liquidity effect on correlation, negative or positive, depending on the financial market environment. Understanding the potential liquidity effect on asset correlations would allow portfolio managers to make more informed decision on optimal portfolio allocation decisions, especially in times of financial distress when liquidity is low. Thus, by including liquidity as a predictor variable in forecasting models for correlation, fund managers can formulate optimal portfolio allocations conditional on the state of liquidity in the market. To that end, the analysis can open the path to a liquidity-based investment strategy in which liquidity proxies are used to predict asset correlations and compute optimal asset positions accordingly.

Our findings suggest that liquidity indeed has a significant effect on the time-variation in asset correlations, particularly in the case of how bond returns co-move with other asset classes. We observe that higher liquidity risk is associated with lower correlation of bond returns with stocks as well as commodities. While higher volatility is generally found to be associated with increased correlations, consistent with earlier research, we argue that the negative effect of liquidity on correlations is driven by shifts in risk aversion that drives investors to shift funds out of relatively riskier asset classes during periods of market stress. This argument is further supported by the analysis of sub-periods based on the structural breaks in the time series. We see that the negative liquidity effect on correlations is driven by strong results observed during the sub-sample that corresponds to the global financial crisis period when investors' aversion to risk likely experienced a significant regime shift. Interestingly however, we observe the opposite effect when it comes to commodity-equity market correlations. Although we do not observe a significant liquidity effect for the full sample, we find a positive liquidity effect on commodity-stock market correlations during the crisis period, most likely due to investors shifting their funds out of these risky assets into the relatively safer bonds, hence creating a positive correlation effect captured by rising liquidity risk during that period. Nevertheless, our findings suggest that measures of liquidity risk can improve models of correlations and potentially help improve the effectiveness of risk management strategies during periods of turbulence. The rest of the paper is structured as follows: Section 2 will explore past literature on conditional correlation, how to measure it and possible factors that drive the time-variation in correlation. Section 3 will explain the data and methodology employed in the study. Section 4 will discuss the empirical results and section 5 will provide a brief summary to conclude the paper.

\section{Literature Review}

Time varying correlation: Reliable estimates of correlation between financial assets have been the subject of extensive research. As mentioned earlier, correlation plays a critical role in asset pricing and risk allocation exercises. Modern portfolio theory developed by Harry Markowitz (1952) states that diversification plays an imperative role in hedging against individual securities' downturns within a portfolio, placing correlation as the basis of diversification. An optimal decision in forming a portfolio would be to include securities that have low correlations, so that downward movements in one security could be offset by an upward movement in 
another. Later works by Levy and Sarnat (1970), Grubel and Fadner (1971), Lessard (1973) and Solnik (1974) have also emphasized the important role correlation plays in constructing an optimal portfolio in an international context.

The literature offers numerous studies that have tried to explore the nature of correlation. Kaplanis (1988) studied the stability of correlation and covariance matrices between the returns of ten major stock markets. Comparing correlations estimated over sub-periods of 46 months using the likelihood ratio tests, he failed to reject the null hypothesis that the correlation matrix is constant over two adjacent sub-periods, hence concluded that correlation was stable over time. Ratner (1992) also claimed that the international correlations remained constant over the period between 1973 and 1989. However, contrast to this literature, studies by Koch and Koch (1991), Von Furstenberg and Jeon (1989), King, Sentana and Wadhwani (1994) and Longin and Solnik (1995) reported opposite results. Koch and Koch (1991) investigated how dynamic linkages among the daily rates of return of eight national stock indexes have evolved since 1972. A dynamic simultaneous equations model (the Chow test) was employed to show that correlation was time varying. A similar conclusion was reached by Von Furstenberg and Jeon (1989) using a vector autoregression model (VAR) for four markets and a very short time period between 1986 and 1988, which King, Sentana and Wadhwani (1992) claimed was possibly due to a transitory increase caused by the 1987 crises. Longin and Solnik (1995) studied the correlation of monthly excess returns for seven major countries over a longer period between 1960 and 1990. They used a multivariate generalized autoregressive conditional heteroskedasticity (GARCH) model and found that the international covariance and correlation matrices are unstable over time. Recent papers including Moskowitz (2003), DeMiguel, Garlappi and Uppal (2009), Chong and Miffre (2010) and Adrian and Brunnermeier (2016) also recognised that correlation was non-stationary. All this evidence, therefore has led to a general consensus that correlations among financial assets have timevarying patterns driven by changes in market characteristics.

Measures of time-varying correlation: With the variety of measures that can be used to measure comovement, the mission for reliable estimates of correlations between financial asset returns has been the motivation for numerous academic studies. Engle, Granger, and Kraft (1984) present an early version as "a bivariate generalization of Engle's ARCH model". This view is conceptually appealing and has found widespread use in practice. This was later extended to GARCH-type models. According to Tse and Tsui (2002), this extension follows a traditional autoregressive moving average time series analogy. It is very broad and includes a large number of parameters while empirical applications require further limitations. Because of its computational simplicity, the CC-MGARCH model is widely used in empirical research. However, although the constant-correlation assumption in this framework provides a convenient MGARCH model for estimation, many studies find that this assumption is not supported by financial data (e.g. Tse and Tsui, 2002). In a recent study, Adams, Füss, and Glück (2017) provide evidence that spurious correlation dynamics occur in response to financial shocks that are large enough to cause a structural break in the timeseries of correlations. As a result, they argue that a rolling-window sample correlation is often a better choice for empirical applications in finance. Not only are rolling-window sample correlations simple, they are an effective way to measure dynamic correlations and lead to better portfolio performance.

Determinants of conditional correlation: Fang , Yu, and Lia (2017) stated that not only is correlation important for investment diversification and risk management, it is helpful for policy makers and portfolio managers to understand the factors driving the long-run correlations related to macroeconomic variables. Studying how the changes in correlation between crude oil and the US stock market movements are related to economic policy uncertainty, the authors found that policy uncertainty has a positive impact on correlation. Most studies in the literature, however, found that correlation changes with the size of market movements (or the volatility of market returns). Examining the time-varying correlations between fixed income securities, stocks and commodities, Chong and Miffre (2010) found that the correlation between commodities and stocks fall in times when market risk is high. Furthermore, the correlation between fixed income securities and stocks were found to decrease in times of high volatility with a rise in volatility in fixed income securities accompanied by a decrease in correlation between the two asset classes. This suggests that diversification benefits of commodities are not as large in periods of volatile long-term interest rates, unlike stocks and short-term interest rate instruments. 
Although the findings that correlations vary over time does not necessarily imply that correlations depend on the size of market movements, evidence was found that correlations increase during periods of decreasing global market returns. Campbell, Koedijk and Koftnan (2002) found that correlations among international equity returns increase in bear markets. This suggests that large negative returns from international equity markets tend to increase co-movements among asset classes. This was also evident during the past financial crises. Moro and Beker (2016) characterise financial crises as the combination of asymmetric information and illiquidity that gives rise to the possibility of a banking crisis, a situation whereby all depositors want their cash back. They further state that a security crisis is associated with an increase in demand for liquidity or more liquid securities. These findings are in line with the earlier finding by Amihud, Mendelson and Wood (1990) that the crash of 1987 occurred in part because of a rise in market illiquidity. This then raises a question as to whether liquidity actually does affect the time-variation in correlations between two asset classes and/or amplifies the effect of volatility on correlation dynamics.

Liquidity: Liquidity, a fundamental concept in finance, can be characterized as the capacity to trade an asset quickly and at low cost. Standard equilibrium asset pricing models assume that markets are free from imperfections, hence disregard the trading costs as well as whether or not an asset can be traded in a reasonable amount of time. The recent financial crises, however, suggested that at times of severe market conditions, liquidity can decline or even vanish. Such liquidity shocks are a potential channel through which asset prices are influenced beyond which can be explained by standard models. Amihud and Mendelson (1986) stated that improved liquidity is expected to increase security values because rational investors dicount secutrities more heavily in the presence of higher trading costs (holding other things equal). This was further supported by Pástor amd Stambaugh (2003) who stated that it is reasonable to expect investors to require higher returns for illiquid assets, implying that liquidity does have an impact on returns. Other studies by Gady , David and Gottesman (2000);Jones (2002) and Amihud (2002) also show that liquidity has predictive power over expected returns. A number of studies documented liquidity to be low in times of financial distress. Chordia, Roll and Subrahmanyam (2001) observed that liquidity measures plummeted in down markets and Jones (2002) found that the sharp decline in liquidity often coincided with market downturns. These studies, however, haveproposed different measures of liquidity in their empirical analysis (Muneer et al., 2011). Pástor and Stambaugh (2003) who also proposed an alternative measure of liquidity based on the dollar volume of stocks in the market, found that liquidity showed a sharp decline during Russian debt crises, the political unrest of 1970 in the US and the Asian fiancial crises in 1997. These are events characterised by high volatility in financial markets and increased correlation between different asset classes as they all experience a large decline in market returns.

Earlier studies on liquidity were primarily focused on its cross-sectional determinants, and were limited to equity markets (e.g., Benston and Hagerman, 1974; and Stoll, 1978)). As more data became available, recent studies have moved their attention to the time-series properties of liquidity in equity and fixed-income markets. Chordia, Roll and Subrahmanyam (2000), Huberman and Halka (2001) and Hasbrouck and Seppi (2001) reported shared characteristics in trading activity and liquidity in the equity markets. Chordia, Roll and Subrahmanyam, (2001) studied daily aggregate equity market spreads, depths and trading activity over an extended period to show weekly regularities in equity liquidity and the influence of market returns, volatility and interest rates on liquidity. In other studies, Fleming (2003) analysed the time-series of a set of liquidity measures for the bond market; Huang, Cai and Wang (2001) related liquidity to return volatility, while Brandt and Kavajecz (2004) studied the relationship between liquidity, order flow and the yield curve. Similarly, Fleming and Remolona (1999) and Balduzzi, Elton and Clifton (2001) analysed returns, spreads, and trading volume in bond markets around economic announcements. However, there have been very few studies on how the time-variation in market liquidity relates to correlation dynamics. Although it has been found that correlation increases in times of bearish markets and times of extreme financial distress, i.e. periods that can be characterised with low liquidity, there have been limited studies on how liquidity could potentially amplify the effect of volatility of conditional correlations. Therefore, this paper investigates the role of market liquidity on the time-variation in the correlations across major asset classes. 


\section{Data and Methodology}

Data: The dataset includes daily returns for the S\&P 500 index; the S\&P 500 high yield corporate bond index and the S\&P Goldman Sachs commodity index to represent the broad asset classes of equities, bonds and commodities, respectively. The data is sourced from Data stream of Thomson Reuters. Note that daily data is used to compute correlations using rolling windows for each month and all subsequent estimations are performed using monthly data. The data period chosen is solely based on the availability of the data. Since the liquidity data is available from 1988, the S\&P Goldman Sachs commodity index and the S\&P equity index data starts in 1988, while the S\&P 500 high yield corporate bond index data starts in 1995 when it becomes available. In the case of market liquidity, the liquidity measure by Pástor and Stambaugh (2003) is publicly available on Lubos Pastor's website.

Variables Specification: Table 1 presents the descriptions of the primary variables of interest in our estimations. The measure of liquidity used in this paper follows the work of Pástor and Stambaugh (2003). In their model, market liquidity in a given month is estimated as an equally weighted average of liquidity measures of individual stocks computed using daily data within a month. In this methodology, the liquidity of stock $i$ in month $t$ is estimated as the OLS estimate for $\gamma_{i, t}$ in the following regression:

$r_{i, d+1, t}^{e}=\theta_{i, t}+\Phi_{i} r_{i, d, t}+\gamma_{i, t} \operatorname{sign}\left(r_{i, d, t}^{e}\right) \cdot v_{i, d, t}+\epsilon_{i, d+1, t}$

where $r_{i, d, t}$ is the return on stock $i$ on day $d$ in month $t, r_{i, d, t}^{e}=r_{i, d, t}-r_{m, d, t}$ with $r_{m, d, t}$ as the value-weighted market return on day $d$ in month $t$. $v_{i, d, t}$ is the dollar volume for stock $i$ on day $d$ in month $t$. Although the OLS slope coefficient $\hat{\gamma}_{i, t}$ is an imprecise estimate of a given stock's $\gamma_{i, t}$, the market-wide average liquidity in month $t$ is estimated more precisely. Pástor and Stambaugh, (2003) argue that the disturbances in equation (1) are less than perfectly correlated across stocks, therefore, the higher the number (N) of stocks included in the portfolio, the more precisely liquidity can be estimated as

$\hat{\gamma}_{t}=\left(\frac{1}{N}\right) \sum_{i=1}^{N} \hat{\gamma}_{i, t}$

Having estimated the liquidity betas for each stock, Pástor and Stambaugh, (2003) then sort the stocks by their liquidity betas and assign stocks to 10 portfolios based on their risk exposures with respect to liquidity. The traded liquidity factor is the value-weighted return on the 10-1 portfolio, reflecting the return spread between stock portfolios with high and low liquidity exposures. Finally, the authors show that this traded liquidity factor has a positive and significant alpha, implying that liquidity risk is indeed priced in the crosssection of returns. Hence, their measure of liquidity is more of a measure of the cost of liquidity or liquidity risk rather than liquidity itself. In our application, we use the traded liquidity factor as our measure of liquidity, i.e. Liquidity ${ }_{t}$, in month $t$.

In the case of volatility, we use daily return data to calculate the realised volatility each month as the sum of daily squared returns over a month (Andersen and Bollerslev, 1998) for each asset (commodities, stocks and bonds) using the formula

$R V_{t}=\sum_{i=1}^{M} r_{i}^{2}$

where $r_{i}$ is the return on the asset class on day $i$ and $M$ is the number of daily returns in the month. Having computed the realised volatility values for each asset class (i) for each month $(t)$, we then create a dummy variable $D_{-} R V_{i, t}$ to represent months of high volatility for each asset class so that the dummy takes on the value of one if the realised volatility for asset class (i) in a given month exceeds the median realised volatility and zero otherwise.

\section{Model Specification}

Rolling-window sample correlation: Before we test the effect liquidity on time-varying correlations, we first examine whether correlations between commodities, stocks and corporate bonds change overtime. As mentioned above, Adams, Füss and Glück (2017) argue that a rolling- window sample correlation is often a better choice for empirical applications in finance. As the authors note, not only is rolling-window sample correlation simple, but it is also an effective way to measure dynamic correlations and lead to better portfolio 
performance. Rolling analysis in this context is outlined by Zivot and Wong (2006) who state that rolling analysis of a time series model is often used to assess the model's stability over time. The factors that drive fluctuations in financial time series often change with the economic environment. Hence, a common technique to assess the stability of a model's parameters is to compute parameter estimates over a rollingwindow of a fixed size through the sample. In the event that the parameters are really consistent over the whole sample, then the estimates over the rolling-windows should be consistent with this pattern.

In our empirical study, we estimate the time-varying correlations using a rolling window size of 60 months. We then test the significance of the estimated correlations using the following t-statistics:

$$
t-s t a t=\frac{\widehat{\rho}_{i j, t} \sqrt{n-2}}{\sqrt{1-\widehat{\rho}_{i j, t}^{2}}}
$$

where $\hat{\rho}_{i j, t}$ is the correlation between asset $i$ and $j$ in montht, $n$ is the window size, i.e. 60 months. The tstatistics are then evaluated with the critical t-statistic at $5 \%$ confidence level of \pm 1.96 in order to ascertain the significance of the correlations.

Regression analysis with structural breaks: Having computed time-varying correlations, we then estimate the following model to determine whether liquidity has any effect on the correlations and whether the liquidity effect is amplified during periods of high volatility

$\hat{\rho}_{i j, t}=\alpha+\beta_{1} *$ liquidity $_{t}+\beta_{2} * D_{-} R V_{i, t}+\beta_{3} * D_{-} R V_{j, t}+\varepsilon_{t}$

where $\hat{\rho}_{i j, t}$ is the rolling correlation between asset $i$ and $j$, estimated using 60-monthrolling window size, $D_{-} R V_{i, t}$ is the dummy for high realised volatility for asset classi. In addition to the whole sample estimations, the model is also estimated with multiple breaks in order to account for structural changes in the data with unknown dates using Bai and Perron (2003) test of multiple structural breaks. In particular, we apply the powerful UDmax and WDmax tests to detect 1 to $M$ structural breaks in the relationship between the correlations and the explanatory variables, allowing for heterogenous error distributions across the breaks.

\section{Empirical Results}

Full sample and rolling correlations: Table 2 presents the unconditional correlations among all asset classes over the whole sample period. We observe that the correlations are all positive and statistically significant although they are rather weak, suggesting that these assets classes can serve as diversifiers for each other. Figure 1 presents the estimated rolling correlations for commodities and stocks along with the rolling-window t-stats computed. The t-statistic critical value at $5 \%$ significance level (i.e., +1.96 and -1.96 ) is represented by the red dotted lines in the plots for t-stats. Examining the correlations for commodities and stocks, we observe notable variation in correlation dynamics across all pairs of assets. Examining the t-stats in Figure 1, we see that correlation is significant specifically between the year 1992 and 1994, as well as during the period between 2008 and 2016. ${ }^{1}$ The positive correlations observed during the post global financial crisis period suggest a coupling of these two asset classes, driving directional similarity in their returns. This period is also characterized by a strong coupling of oil market movements with the stock market (Bernanke, 2016). Similar results are observed in Figure 2 for the correlation between commodities and bonds, with significant correlations observed in 2001 as well as between 2008 and 2014, following the global financial crisis. Likewise, we observe significant time-variation in the correlation between stocks and bonds presented in Figure 3, with significant positive correlations observed during the post-global financial crisis period. These correlation estimates are consistent with the earlier studies by Koch and Koch (1991), Von Furstenberg and Jeon (1989), King, Sentana and Wadhwani (1994) and Longin and Solnik (1995) which found that correlation is time variant. Hence, we proceed to investigate whether liquidity plays any role in this process, and if yes, how it affects the time-variation in correlations, especially during periods of high volatility.

\footnotetext{
${ }^{1}$ We also used a rolling window approach with 120 observations. Our results were qualitatively similar and are available upon request from the authors.
} 
OLS regression results with breaks: Having estimated the time-varying correlations, we next estimate equation (5) for each pair of assets. Table 3 presents the findings for commodity-stock market correlations. Looking at the results for the full sample, we see that the realised volatility of commodities and stocks have a positive impact on changes in correlation between the two asset classes, although only realised volatility of commodities is significant. When breaks are introduced, realised volatility is found to have a significant positive relationship with conditional correlation between 1992 and 1996, as well as 2001 and 2008. Considering that the period between 1992 and 1996 was the dot-com era where investors were over excited on the new technology stocks driving the bubble during that period, and the commodity boom took place during the 2001-2008 period, the findings are in line with the previous evidence that high volatility has a positive effect on conditional correlations in times of bullish markets (Campbell, Koedijk and Koftnan, (2002)). Campbell et al (2002) also found that high volatility has a positive relationship with conditional correlation in times of bearish markets, supporting the general positive relationship between conditional correlation and high volatility.

In the case of liquidity, we see that liquidity has a negative effect on the correlation between commodities and stocks. When breaks are introduced, we see that liquidity has a significant negative effect, particularly during the boom years of the dot-com era between 1992 and 1996. However, during the 2008 financial crises, liquidity is found to have a positive effect on conditional correlation. Hence, it seems that liquidity tends to affect correlations negatively during volatile periods. However, in times of high volatility accompanied by financial distress, liquidity has a positive relationship with correlation. During recessions or financial crises liquidity tends to be low and correlation between commodities and stocks rises, hence, the negative relationship between liquidity and time-varying correlation between the two securities. A significant investment implication of this finding is that active managers can use liquidity fluctuations to shift funds and in and out of these asset classes in order to generate excess returns. For example, by tracing market liquidity measures, one can devise a conditional investment strategy that shifts between staying focused during periods of high liquidity and diversifying into other assets during periods of low liquidity. Furthermore, given the interaction of volatility with liquidity, the above strategy can further be conditioned on the state of the market in terms of volatility.

Examining Table 4 for the correlation between commodities and bonds, we see that realised volatility of commodities and bonds both have a negative relationship with conditional correlation, although they are not significant in the full sample. When breaks are introduced, realised volatility of bonds is significant with a negative sign between 2000 and 2003, the commodity boom period. In the same period, high volatility of commodities had a positive effect of correlation. This is in line with Chong and Miffre (2010) who found that a rise in volatility in fixed-income securities such as bonds is accompanied by a decrease in correlation between the two asset classes. This suggests that unlike bonds, the benefits of diversification coming from commodities have less impact in periods when market returns are highly volatile. However, considering the time of the financial crises of 2008, time varying correlation of both assets had a positive relationship with conditional correlation. On the other hand, liquidity is found to generally have a negative relationship with correlation. When the breaks are introduced, unlike correlation between commodities and stocks where liquidity was found to have a positive effect on conditional correlation during the 2008 crises, liquidity now has a negative relationship with conditional correlation during the same period. This suggests in times of high volatility both asset classes are good for diversification as they experience lower correlation. However, considering the years between 2006 and 2009, the financial crises period, the high volatility in both securities had a positive effect on correlation. This suggests that the two asset classes are good for diversification in times of high liquidity, but not as much in times of low liquidity when markets are under stress.

In the case of correlation between stocks and bonds reported in Table 5, we observe similar results for the volatility effect on correlations as we observed for the other assets. We see that the realised volatility of stocks has a significant and positive effect on correlation. When breaks are introduced, however, we observe that realised volatility of both asset classes have a negative impact on time-varying correlations during the commodity boom years. It is possible that the financializing commodities during this period created an influx of stock market investors shifting funds across stock and commodity funds, thus creating a coupling of stock and commodity markets (consistent with the positive volatility effect in Table 3), leading to a lower association between bond and stock markets. However, considering the years between 2008 and 2011, the 
financial crises period, the high volatility in both securities has a positive effect on correlation, implying that these two asset classes are good for diversification in times of high liquidity, but not as much in times of low liquidity when financial markets are under stress.

Consistent with the earlier results, looking at the full sample results, we see that liquidity has a negative effect on time-varying correlations. When breaks are introduced, liquidity is found to have a significant negative effect, particularly in the aftermath of the dot-com crash and the financial crises of 2008. Fang, Yu and Lia (2017) find that during recessions or financial crises when uncertainty tends to be high, correlation between stocks and bonds rises. Times of high uncertainty tend to have low liquidity, hence, the negative relationship between liquidity and time-varying correlation between the two securities. In short, we show that correlations indeed have a time-varying nature and liquidity serves as a strong driver of correlations with heterogeneous effects across different asset classes. Particularly in the case of the correlations of bonds with stocks and commodities, we see that liquidity has a negative effect on correlations, while volatility has a positive marginal effect. Hence, based on these results, one can argue that the combinations of commodities and bonds particularly can yield diversification benefits during normal times and not times of market stress. This implies that investors should use an amended variance-covariance matrix for portfolio analysis and risk management when concerned about downside risk (Campbell, Koedijk and Koftnan, 2002) and measures of liquidity can be used to improve the efficiency of portfolio and/or risk management models.

\section{Conclusion}

Correlations are critical inputs for many of the common tasks of financial management, specifically in forming an optimal investment portfolio. Furthermore, it is of high importance for policy makers and portfolio managers to understand the factors driving the long-run correlations related to macroeconomic and financial variables. There has been extensive work in measuring and understanding the basis for the time-variation in correlations. Moro and Beker (2016) characterise financial crises as the combination of asymmetric information and illiquidity that gives rise to the possibility of a banking crisis, a situation whereby all depositors want their cash back. They further state that a security crisis is associated with an increase in demand for more liquid securities. This suggests that correlation between two securities would possibly be affected by liquidity, which raises a question as to whether the change in liquidity could potentially be the driver of conditional correlations among different asset classes.

Our findings suggest that liquidity indeed has a direct effect on the time-variation in asset correlations, particularly in the case of how bond returns comove with other asset classes. We observe that higher liquidity risk is associated with lower correlation of bond returns with stock as well as commodities. While higher volatility is generally found to be associated with increased correlations, consistent with earlier research, it can be argued that the negative effect of liquidity on correlations is driven by shifts in risk aversion that drives investors to shift funds out of relatively riskier asset classes during periods of market stress. This argument is further supported by the analysis of sub-periods based on the structural breaks in the time series. We see that the negative liquidity effect on correlations is driven by strong results observed during the sub-sample that corresponds to the global financial crisis period when investors' aversion to risk likely experienced a significant regime shift. Interestingly however, we observe the opposite effect when it comes to commodity-equity market correlations. Although we do not observe a significant liquidity effect for the full sample, we find a positive liquidity effect on commodity-stock market correlations during the crisis period, most likely due to investors shifting their funds out of these risky assets into the relatively safer bonds, hence creating a positive correlation effect captured by rising liquidity risk during that period.

The liquidity effect on asset correlations and its interaction with market volatility can be utilized to devise active portfolio management strategies, conditional on the state of market liquidity. Since the traded liquidity factor used in our empirical analysis can be computed and updated using stock price data, one can identify thresholds on the level of liquidity and use this threshold as a signal to shift funds and in and out of these asset classes in order to generate excess returns. For example, by tracing market liquidity measures, one can devise a conditional investment strategy that shifts between staying focused during periods of high liquidity and diversifying into other assets during periods of low liquidity. Furthermore, given the interaction of volatility with liquidity, the above strategy can further be conditioned on the state of the market in terms of 
volatility in order to avoid large losses that can be sustained due to increased asset correlations. Overall, our findings suggest that measures of liquidity risk can improve models of correlations and potentially help improve the effectiveness of diversification strategies during periods of turbulence. There relationships are important to consider, especially in times of financial distress where huge losses could be experienced.

\section{References}

Adams, Z., Füss, R. \& Glück, W. G. (2017). Are correlations constant? Empirical and theoretical results on popular correlation models in finance. Journal of Banking and Finance, 84, 9-24.

Adrian, T. \& Brunnermeier, M. (2016). CoVaR. American Economic Review, 106(7), 1705-1741.

Amihud, Y. (2002). Illiquidity and stock returns: Cross-section and time-series effects. Journal of Financial Markets, 5(1), 31-56.

Amihud, Y. \& Mendelson, H. (1986). Asset pricing and the bid-ask spread. Journal of Financial Economics, 17(2), 223-249.

Amihud, Y., Mendelson, H. \& Wood, R. (1990). Liquidity and the 1987 stoc market crash.Journal of Porfolio Management, 16 (3), 65-69.

Andersen, T. G. \& Bollerslev, T. (1998) Answering the skeptics: Yes, standard volatility models do provide accurate forecasts. International Economic Review, 39(4), 885-905.

Bai, J. \& Perron, P. (2003) Computation and analysis of multiple structural change models. Journal of Applied Econometrics, 18(1), 1-22.

Balduzzi, P., Elton, E. J.\& Clifton , T. (2001). Economic news and bond prices: Evidence from the US treasury market. The Journal of Financial and Quantitative Analysis, 36(4), 523-543.

Benston, G. J.\& Hagerman, R. L. (1974). Determinants of bid-asked spreads in the over-the-counter market. Journal of Financial Economics, 1, 353-364.

Bernanke, B. 2016. The relationship between stocks and oil prices. Brookings. https://www.brookings.edu/blog/ben-bernanke/2016/02/19/the-relationship-between-stocksand-oil-prices/

Boyer, B. H., Gibson, M. S. \& Loretan, M. (1999). Pitfalls in tests for changes in correlations. Board of Governors of the Federal Reserve System, Federal Reseve Bank International Finance Discussion Papers no. 597.

Brandt, M. W.\& Kavajecz, K. A. (2004). Price discovery in the US treasury market: The impact of orderflow and liquidity on the yield curve. The Journal of Finance, 59(6), 2623-2654.

Campbell, R., Koedijk, K.\& Koftnan, P. (2002). Increased correlation in bear markets. Financial Analysts Journal, 58(1), 87.

Chong, J.\& Miffre, J. (2010). Conditional correlation and volatility in commodity futures and traditional asset markets.Journal of Alternative Investments, 12(13), 61-75.

Chordia, T., Roll, R.\& Subrahmanyam, A. (2000). Commonality in liquidity. Journal of Financial Economics, 56(1), 3-28.

Chordia, T., Roll, R.\& Subrahmanyam, A. (2001). Market liquidity and trading activity. The Journal of Finance, 56(2), 501-530.

DeMiguel, V., Garlappi, L.\& Uppal, R. (2009). Optimal versus naïve diversification: How inefficient is the 1/N portfolio strategy? The Review of Financial Studies, 22(5), 1915-1953.

Engle, R. (2002). Dynamic conditional correlation: A Simple class of multivariate generalized autoregressive conditional heteroskedasticity models. Journal of Business \& Economic Statistics, 20(3), 339-350.

Engle, R. F., Granger, C. W.\& Kraft, D. (1984). Combining competing forecasts of inflation using a bivariate ARCH model. Journal of Economic Dynamics and Control, 8, 151-165.

Fang, L., Yu, H.\& Lia, L. (2017). The effect of economic policy uncertainty on the long-term correlation between US stock and bond markets. Economic Modelling, 66, 139-145.

Fleming, M. J. (2003). Measuring treasury market liquidity. Economic Policy Review, 9(3), 83-108.

Fleming, M. J.\& Remolona, E. M. (1999). Price formation and liquidity in the us treasury market: The response to public information. The Journal of Finance, 54(5), 1901-1915.

Gady , J., David , J.\& Gottesman, A. A. (2000). The capital asset pricing model and the liquidity effect: A theoretical approach. Journal of Financial Markets, 3(1), 69-81.

Grubel, H.\& Fadner, K. (1971). The interdependence of international equity markets. Journal of Finance, 26(1), 89-94. 
Hasbrouck, J.\& Seppi, D. J. (2001). Common factors in prices, order flows, and liquidity. Journal of Financial Economics, 59(3), 383-411.

Huang, R., Cai, J.\& Wang, X. (2001). Information-based trading in the treasury note interdealer broker market. Journal of Financial Intermediation, 11(3), 269-296.

Huberman, G. \& Halka, D. (2001). Systematic liquidity. The Journal of Financial Research, 24(2), 161-178.

Jones, C. M. (2002). A century of stock market liquidity and trading costs. Graduate School of Business, Columbia University.

Jung, K. M. (2017). Liquidity risk and time-varying correlation between equity and currency returns. Economic Inquiry, 55 (2), 898-919.

Kaplanis, E. C. (1988). Stability and forecasting of the co-movement measures of international stock returns. Journal of International Money and Finance, 7(1), 63-75.

King, M., Sentana, E.\& Wadhwani, S. (1994). Volatility and links between national stock.Econometrica, 62(4), 901-933.

Koch, P. D.\& Koch, T. W. (1991). Evolution in dynamic linkages across national stock indexes. Journal of International Money and Finance, 10(1), 231-251.

Lessard, D. R. (1973). International portfolio diversification: a multivariate analysis for a group of latin american countries. The Journal of Finance, 28(1), 619-633.

Levy, H.\& Sarnat, M. (1970). International diversification of investment portfolios.American Economic Review, 60(4), 668-675.

Longin, F.\& Solnik, B. (1995). Is the correlation in international equity returns constant: 1960-1990? Journal of International Money and Finance, 14(1), 3-26.

Loretan, M.\& English, W. B. (2000). Evaluating 'correlation breakdowns' during periods of market volatility'. Federal Reserve Bank, International finance Discussion Papers no. 658.

Markowitz, H. (1952). Portfolio Selection. The Journal of Finance, 7(1), 77-91.

Moro, B. \& Beker, V. A. (2016). Modern Financial Crises (1st ed.). Kansas City: Springer International Publishing.

Moskowitz, T. J. (2003). An analysis of covariance risk and pricing anomalies. The Review of Financial Studies, 16(2), 417-457.

Muneer, S., Butt, B. Z. \& Rehman, K. U. (2011). A Multifactor Model of Banking Industry Stock Returns: An Emerging Market Perspective. Information Management and Business Review, 2(6), 267-275

Pástor, L.\& Stambaugh, R. (2003). Liquidity risk and expected stock returns. Journal of Political Economy, 111(3), 642-685.

Ramchand, L.\& Susmel, R. (1998). Volatility and cross correlation across major stock markets. Journal of Empirical Finance, 5(4), 397-416.

Solnik, B. H. (1974). An equilibrium model of the international capital market. Journal of Economic Theory, $8(4), 500-524$.

Stoll, H. (1978). The supply of dealer services in securities markets. Journal of Finance, 33(4), 1133-1151.

Tse, Y. K.\& Tsui, A. K. (2002). A multivariate generalized autoregressive conditional heteroscedasticity model with time-varying correlations. Journal of Business and Economic Statistics, 20(3), 351-362.

Von Furstenberg, G. M.\& Jeon, B. N. (1989). International stock prices movements: Links and messages. Brookings Papers on Economic Activity, 1, 125-179.

Zivot, E.\& Wong, J. (2006). Modelling Financial Times Series with S-Plus. Washington: University of Washington .

Table 1: Variable names and description

\begin{tabular}{cl}
\hline Name & Description \\
\hline$\hat{\rho}_{i j, t}$ & Time-varying correlation between asset $i$ and $j$ in month $t$. \\
Liquidity & Traded liquidity in month $t$. \\
$D_{-} R V_{i, t}$ & Dummy on realised volatility for asset $i$ in month $t$. \\
\hline
\end{tabular}


Table 2: Full sample correlations

\begin{tabular}{llll}
\hline & Commodities & Stocks & Bonds \\
\hline Commodities & 1 & & \\
Stocks & $0.1003^{* * *}$ & & \\
& {$[2.0165]$} & 1 & \\
\multirow{3}{*}{ Bonds } & $0.1030^{* *}$ & $0.1455^{* *}$ & \\
& {$[1.6735]$} & {$[2.3757]$} & 1 \\
\hline
\end{tabular}

Note: ${ }^{* * *, * *}, *$ represent $1 \%, 5 \%$ and $10 \%$ significance levels respectively with $\mathrm{t}$-statistics in square brackets.

Table 3: commodities and stocks

\begin{tabular}{llll}
\hline$\widehat{\boldsymbol{\rho}}_{\boldsymbol{c s} \boldsymbol{t} \boldsymbol{t}}$ & $\boldsymbol{D}_{-} \boldsymbol{R} \boldsymbol{V}_{\boldsymbol{c}, \boldsymbol{t}}$ & $\boldsymbol{D}_{-} \boldsymbol{R} \boldsymbol{V}_{\boldsymbol{s}, \boldsymbol{t}}$ & liquidity $_{\boldsymbol{t}}$ \\
\hline Full sub-sample & $0.137^{* * *}$ & 0.014 & -0.509 \\
& $(0.000)$ & $(0.618)$ & $(0.176)$ \\
& {$[4.822]$} & {$[0.499]$} & {$[-1.356]$}
\end{tabular}

Breaks:

\begin{tabular}{llll} 
1988M03 - 1992M05 & -0.039 & 0.022 & 0.335 \\
& $(0.241)$ & $(0.422)$ & $(0.297)$ \\
& {$[-1.175]$} & {$[0.804]$} & {$[1.044]$} \\
1992M06 - 1996M08 & $0.184^{* * *}$ & $0.145^{* * *}$ & $-0.915^{* * *}$ \\
& $(0.000)$ & $(0.000)$ & $(0.004)$ \\
& {$[4.594]$} & {$[3.913]$} & {$[-2.868]$} \\
$1996 M 09-2001 M 01$ & -0.016 & $-0.095^{* * *}$ & -0.080 \\
& $(0.443)$ & $(0.000)$ & $(0.782)$ \\
& {$[-0.768]$} & {$[-3.563]$} & {$[-0.278]$} \\
$2001 M 02-2008 M 06$ & $0.059^{* * *}$ & -0.017 & -0.151 \\
& $(0.004)$ & $(0.290)$ & $(0.500)$ \\
& {$[2.916]$} & {$[-1.059]$} & {$[-0.675]$} \\
$2008 M 07-2012 M 09$ & -0.041 & -0.026 & $0.517^{* *}$ \\
& $(0.183)$ & $(0.457)$ & $(0.037)$ \\
& {$[-1.334]$} & {$[-0.745]$} & {$[2.095]$} \\
$2012 M 10-2016 M 12$ & -0.085 & 0.003 & -0.373 \\
& $(0.000)$ & $(0.919]$ & $(0.456)$ \\
& {$[-3.752]$} & {$[0.101]$} & {$[-0.747]$} \\
\hline
\end{tabular}

Note: $* * *, * *, *$ represent $1 \%, 5 \%$ and $10 \%$ significance levels respectively with $\mathrm{p}$-values in parentheses and $\mathrm{t}$ statistics in square brackets.

Table 4: commodities and bonds

\begin{tabular}{llll}
\hline$\widehat{\boldsymbol{\rho}}_{\boldsymbol{c b}, \boldsymbol{t}}$ & $\boldsymbol{D}_{-} \boldsymbol{R} \boldsymbol{V}_{\boldsymbol{c}, \boldsymbol{t}}$ & $\boldsymbol{D}_{-} \boldsymbol{R} \boldsymbol{V}_{\boldsymbol{b}, \boldsymbol{t}}$ & liquidity $_{\boldsymbol{t}}$ \\
\hline Full sub-sample & -0.032 & -0.012 & $-1.146^{* * *}$ \\
& $(0.319)$ & $(0.714)$ & $(0.007)$ \\
& {$[-0.998]$} & {$[-0.367]$} & {$[-2.694]$}
\end{tabular}

Breaks:

\begin{tabular}{llll}
$2000 M 02$ & 0.018 & $-0.052^{*}$ & -0.467 \\
$2003 M 04$ & $(0.488)$ & $(0.058)$ & $(0.142)$ \\
& {$[0.695]$} & {$[-1.908]$} & {$[-1.476]$} \\
$2003 M 05$ & 0.007 & -0.044 & -0.069 \\
$2005 M 12$ & $(0.826)$ & $(0.134)$ & $(0.896)$ \\
& {$[0.220]$} & {$[-1.505]$} & {$[-0.131]$} \\
$2006 M 01$ & $0.053^{*}$ & $0.134^{* * *}$ & $-0.592^{* *}$ \\
\hline
\end{tabular}




\begin{tabular}{llll}
\hline $2009 M 07$ & $(0.067)$ & $(0.000)$ & {$[0.021)$} \\
& {$[1.838]$} & {$[4.829]$} & {$[-2.323]$} \\
$2009 M 08$ & -0.000 & 0.008 & 0.106 \\
$2013 M 10$ & $(0.996)$ & $(0.736)$ & $(0.779)$ \\
& {$[-0.005]$} & {$[0.338]$} & {$[0.282]$} \\
$2013 M 11$ & 0.041 & $-0.057^{*}$ & -0.005 \\
$2016 M 12$ & $(0.154)$ & $(0.057)$ & $(0.994)$ \\
& {$[1.430]$} & {$[-1.919]$} & {$[-0.008]$} \\
\hline
\end{tabular}

Note: $* * *, * *,+$ represent $1 \%, 5 \%$ and $10 \%$ significance levels respectively with $\mathrm{p}$-values in parentheses and tstatistics in square brackets.

Table 5: stocks and bonds

\begin{tabular}{|c|c|c|c|}
\hline$\widehat{\boldsymbol{\rho}}_{b s, t}$ & $D_{-} R V_{b, t}$ & $D_{-} R V_{s, t}$ & liquidity $_{t}$ \\
\hline \multirow[t]{3}{*}{ Full sub-sample } & -0.025 & $0.089 * * *$ & $-0.800^{* * *}$ \\
\hline & $(0.322)$ & $(0.000)$ & $(0.014)$ \\
\hline & {$[-0.993]$} & [3.594] & {$[-2.519]$} \\
\hline \multicolumn{4}{|l|}{ Breaks: } \\
\hline 2000M02 & $-0.090^{* * *}$ & -0.053 & $-0.549^{* *}$ \\
\hline \multirow[t]{2}{*}{$2002 M 08$} & $(0.000)$ & (0.153) & $(0.024)$ \\
\hline & [-4.121] & [-1.435] & {$[-2.284]$} \\
\hline $2002 M 09$ & -0.015 & $-0.042^{*}$ & -0.218 \\
\hline \multirow{2}{*}{$2006 M 02$} & $(0.465)$ & $(0.062)$ & $(0.519)$ \\
\hline & {$[-0.732]$} & {$[-1.877]$} & {$[-0.646]$} \\
\hline $2006 \mathrm{M03}$ & 0.015 & 0.023 & -0.041 \\
\hline \multirow[t]{2}{*}{ 2008M09 } & $(0.630)$ & $(0.443)$ & $(0.855)$ \\
\hline & [0.482] & [0.769] & [-0.183] \\
\hline $2008 M 10$ & 0.020 & $0.038^{* *}$ & $-0.694^{* * *}$ \\
\hline \multirow[t]{2}{*}{$2013 M 10$} & $(0.231)$ & $(0.022)$ & $(0.001)$ \\
\hline & [1.201] & [2.305] & {$[-3.242]$} \\
\hline 2013M11 & $-0.036^{*}$ & -0.004 & -0.150 \\
\hline \multirow[t]{2}{*}{$2016 M 12$} & $(0.080)$ & $(-0.145)$ & $(0.727)$ \\
\hline & {$[-1.758]$} & {$[0.476]$} & {$[-0.165]$} \\
\hline
\end{tabular}

Note: $* * *, * *,+$ represent $1 \%, 5 \%$ and $10 \%$ significance levels respectively with $\mathrm{p}$-values in parentheses and $\mathrm{t}$ statistics in square brackets.

Figure 1: correlation between commodities and stocks

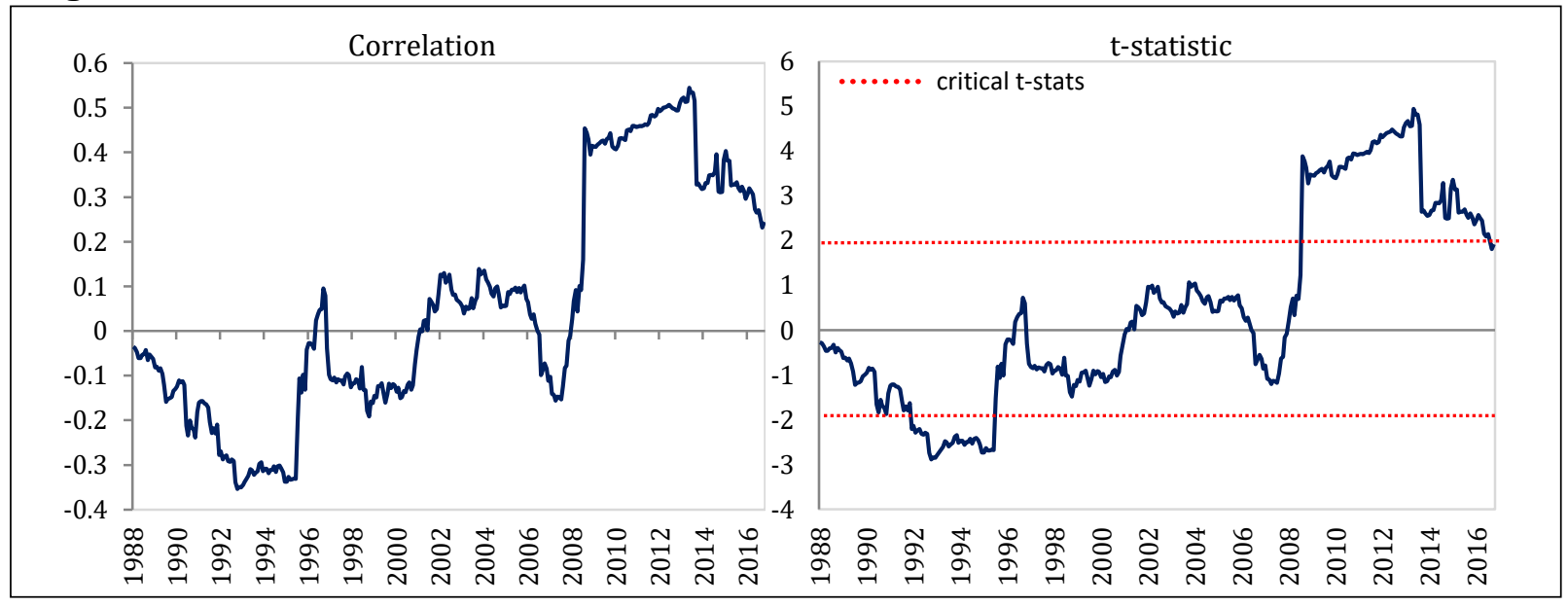


Figure 2: correlation between commodities and bonds

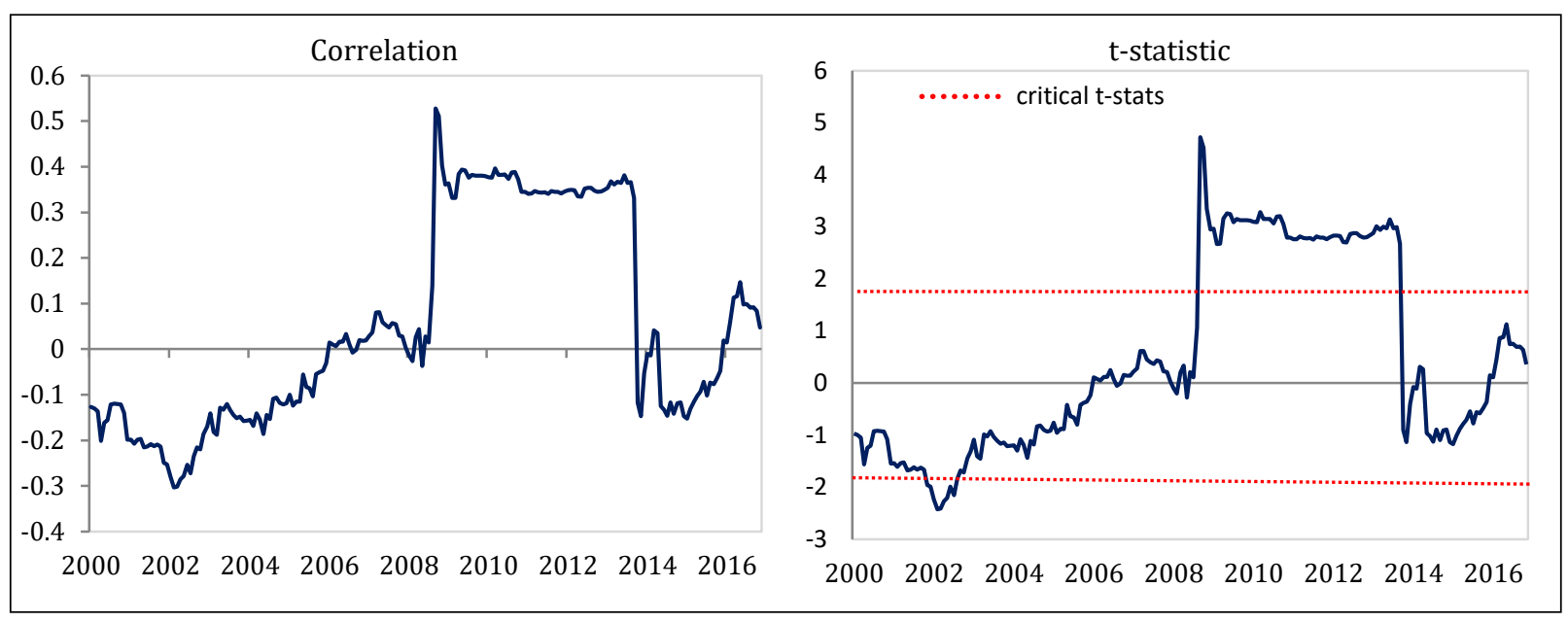

Figure 3: correlation between stocks and bonds

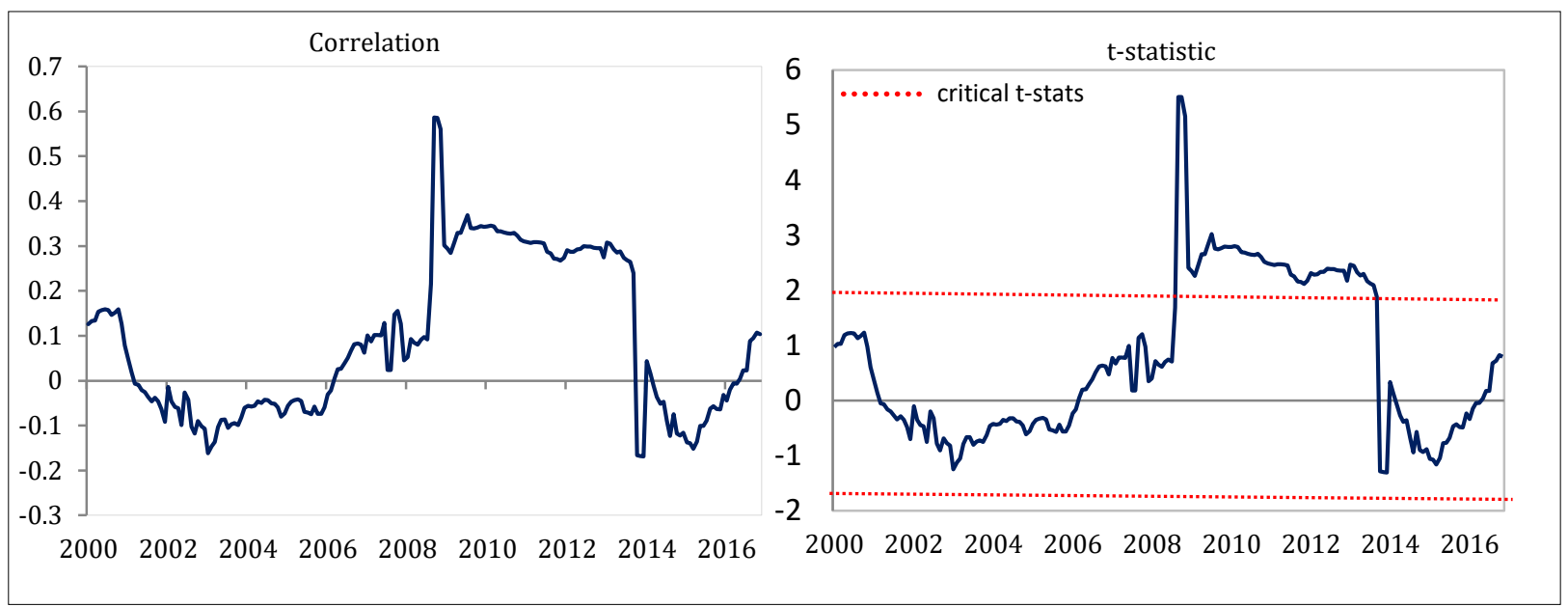

